\title{
Bochdalek hernia (Acute gastric obstruction and laparoscopic approach)
}

\author{
Rafael Diaz-Nieto ${ }^{1 *}$, Alvaro Naranjo-Torres ${ }^{2}$ \\ ${ }^{1}$ Department of General and Digestive Surgery, "Virgen de la Victoria” University Hospital, Málaga, Spain; * Corresponding Author: \\ rafadiaznieto@hotmail.com \\ ${ }^{2}$ Department of General and Digestive Surgery, "Infanta Margarita” Hospital, Cabra-Córdoba, Spain.
}

Received 3 August 2010; revised 20 September 2010; accepted 28 October 2010.

\begin{abstract}
Bochdalek hernia is a rare clinical entity which consist of a lack of development of the diaphragm. Its diagnosis is more common in children and in relation to respiratory symptons. But it is also possible to appear in adulthood and usually related with acute digestive problems. Due to acute presentation often require emergency surgery. After reviewing the current literature, laparoscopic approach seems to be the technique of choice, with or without mesh placement. We report a new case of a young man with acute obstruction syndrome and laparoscopic treatment.
\end{abstract}

Keywords: Cbochdalek Hernia; Gastric Obstruction; Laparoscopic Approach

\section{INTRODUCTION}

Bochdalek hernia is a congenital pathology which consists of an uncomplete development of the diaphragm, which entails the persistence of a hole or weakness in the posterolateral side of the diaphragm. This lack of development can take place at different times of embryogenesis between the sixth and tenth week. If the disorder take place in the sixth-seventh week of gestation, pleuroperitoneales membranes have not been formed yet so there will be a complete absence of hernia sack. But if it happens around the eighth week, these membranes can have been already formed, and what we will found is a diaphragmatic eventration. Bochdalek hernia itself is the first case.

Congenital diaphragmatic hernias are rare (excepting hiatal hernia), and they can be approximately founded one in every 3200 children born alives [1]. Bochdalek hernia is much more frequent compared to MorganyLarry hernia, and also more usual in the left side against the right one. Bilateral cases rise up to $3 \%$ of children $[2,3]$. This can be explained anatomically, as the last side in developing is the right one and also, liver in the left side project the development of hernia across little sacks.

From a clinical point of view, $90 \%$ are diagnosed in childhood and usually asociated with pulmonary hypoplasia due to the compression of the lung. This situation carry on acute hemodinamic and respiratory failure that require treatment. Those in the left side develope chronic symptoms depending on the size [4].

Diagnosis of Bochdalek hernia in adulthood is extremely rare and most cases founded in the literature were diagnosed as acute gastrointestinal problems compared to cardiorrespiratory symptoms, unlike what happens in childhood [5]. Commonly, we found patients who are free of symptoms for years, and suddenly or related to minimal effort or trauma they start with an acute clinical problem. Severe trauma or recent surgery should suggest the presence of a traumatic diaphragmatic rupture. Many diagnostic steps may be useful, as a single x-ray or a gastrointestinal study [5]. But up to date helicoidal tommogrphy seems to be the technique of choice; and magnetic resonance has not already shown benefits except in cases of doubt [6]. Due to in adulthood we are used to find an emergency problem and the differential diagnosis with traumatic rupture of the diaphragm is not always possible, this clinical entity is usually indication of emergency surgery because of the potential complications arising from it [7].

\section{CASE REPORT}

We present the case of a 28 years-old man without medical or surgical pathology; who is examinated in the emergency room due to a lumbar and epigastric pain since two days. In the last 24 hours the patient had developed also oral intolerancy with vomiting. The man did not remember any prior injury or trauma.

The examination showed difficulty breathing, need of air and a mild pain in the abdominal exploration.

Analytically leukocytosis was founded with no other alteration. In the early explorations a chest radiograph 
was included where we observed the stomach above the diaphragma. (Figure 1)

Endoscopy was performed and a gastrointestinal transit reported intrathoracic stomach with possible gastric volvulus due to hiatal hernia as most probable diagnosis. (Figure 2)

Endoscopic decompression and nasograstric aspiration were tried but the evolution was not satisfactory and finally emergency surgery was decided.

Laparoscopic approach was performed. A Bochdalek diaphragmatic hernia was found with gastric, colon and spleen inside thorax (Figures 3 and 4) and without the presence of hernia sack. Laparoscpically we reduced the organs to abdominal cavity (Figure 5), we putted a chest drainage and proceeded to a primary free-tension herniorraphy (Figure 6).

Postoperative course was good and free of respiratory or digestive symptoms. In subsequent clinical and radiological controls, the patient keeps asymptomatic.

\section{DISCUSSION}

Bochdalek hernia was described in 1848 [8]. In adulthood is a very rare clinical entity with very few cases

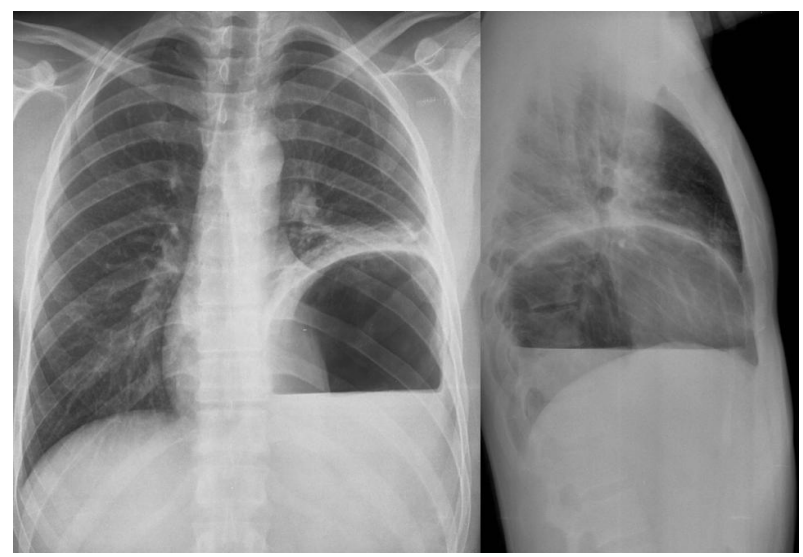

Figure 1. X-Ray at diagnosis moment.

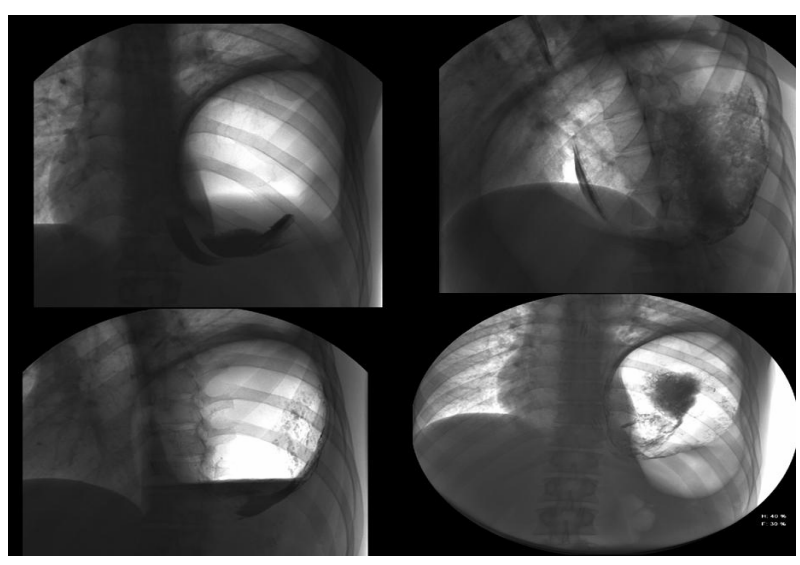

Figure 2. Gastrointestinal study.

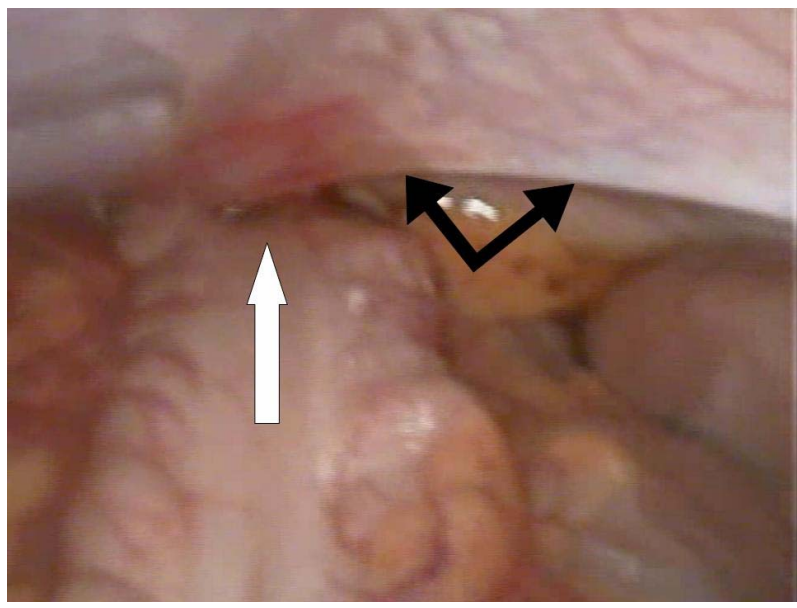

Figure 3. Laparoscopic findings. White arrow: large bowel and double black arrow: diafragm.

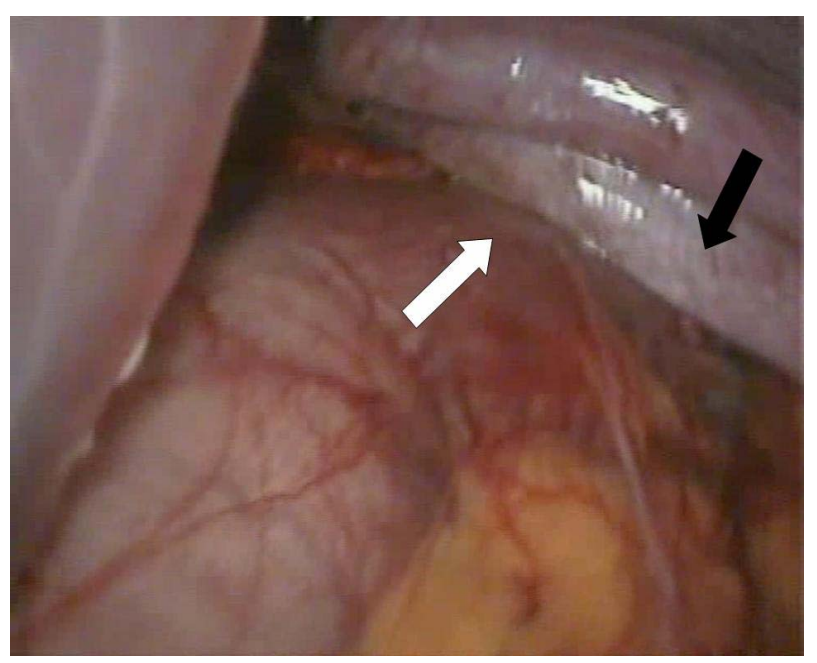

Figure 4. Laparoscopic findings. Stomach after reduction of large bowel into cavity and partial reduction of it (white arrow). Diafragm (black arrow).

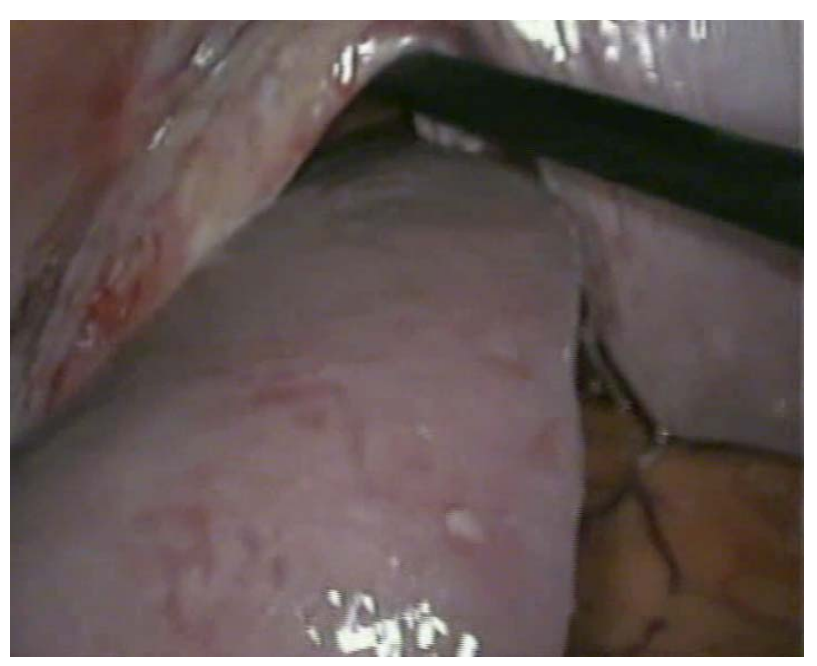

Figure 5. Reduction into cavity of the spleen.

Openly accessible at http://www.scirp.org/journal/HEALTH/ 


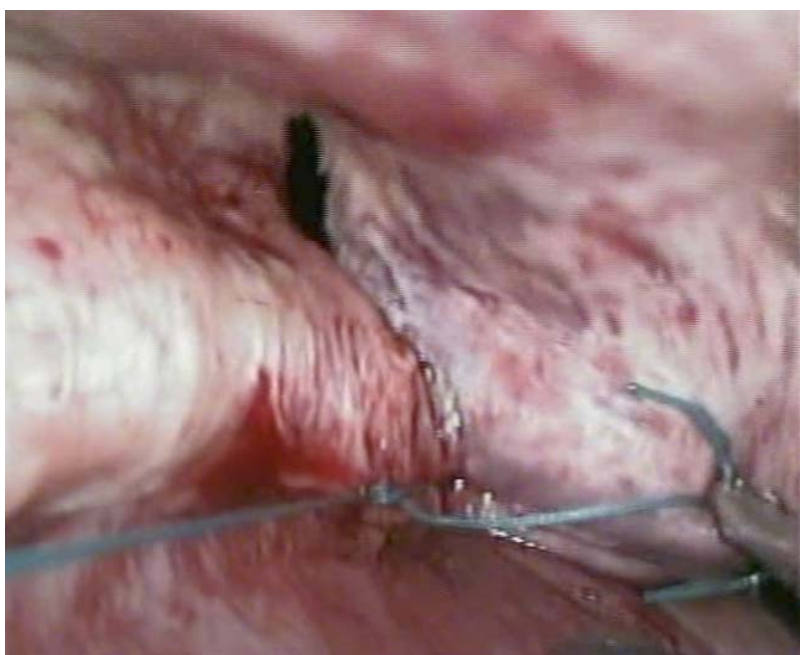

Figure 6. Primary stuture of diafragm.

included in the literature. It can leads us not to pay attention enough to this patology in the emergency room, and a recent review shows that also $38 \%$ of cases were initially wrong diagnosed [5].

Unlike what happens in childhood, clinical manifestations are mainly gastrointestinal and in all cases reviewed in the literature they course as an acute problem or are diagnosed incidentally.

Surgery is the initial treatment due to potencial compliactions, and unless certain exceptions or diagnosis during elective surgery, it is an indication of emergency surgery because his course is indistinguishable from a traumatic rupture of the diafragm [7].

Regarding the type of treatment is where there are some disputes, and generally in relation to the approach. You can try both thoracic and abdominal approaches, with no scientific evidence to support one or the other. Several articles bring cases operated by chest (thoracoscopy or thoracotomy) $[9,10]$ and according to a recent review, this is the most common approach for Morgany-Larry hernia [11] and seems to be a good alternative in case of recurrence after a abdominal approach. But the trend seems to support an abdominal approach due to the potential gastrointestinal complications that may have been caused by the hernia, and that would be better repaired by abdominal approach [12].

Technique itself has also alternatives. The disjunction between laparotomy or laparoscopy appears to be resolved in favor of laparoscopic surgery. Well demonstrated advantages of laparoscopy, are also applicable to this disease, so there are authors who suggest it as the gold standard of this surgery [13] also in cases of acute and chronic presentation if the patient is stable and if done by expert laparoscopic surgeons [14]. Another technical issue is whether or not to place a mesh for the correction of the hernia defect. There is no evidence to support either method. Several authors describe successful without the use of mesh $[10,13,15]$, however the current trend is proceeding to an herniophlastia thanks to the development of meshes that allow them use intraabdominally $[16,17]$. But there is no studies that demonstrate the advantages of either technical or compare the rate of recurrence or long-term results.

\section{CONCLUSION}

The presentation of a Bochdalek hernia in adulthood is rare but is necessary to know it well because, at present, a large number of diagnoses are wrong initially. It usually appears in acute way and usually related to gastrointestinal problems, unlike what happens in childhood, where clinic is mainly respiratory.

Treatment is surgery and the approach we recommend is laparoscopic approach against the thoracic one. Surgeons must be experts in laparoscopy and this type of surgery.

The use of mesh is controversial because of the absence of long-term results but it seems more suitable at present. In the absence of tension or very small defects we can choose a primary suture.

\section{REFERENCES}

[1] Kaiser, J.R. and Rosenfeld, C.R. (1999) A populationbased study of congenital diaphragmatic hernia: Impact of associatedanomalies and preoperative blood gases on survival. Journal of Pediatric Surgery, 34, 1196-1202. doi:10.1016/S0022-3468(99)90151-3

[2] Miller, S. (1994) Diaphragmatic hernia: Resuscitation. Anesthesia and Uncommon Pediatric Diseases. Anesthesiology Review, 366.

[3] Kirks, D.R. (1991) Practical pediatric imaging. 2nd Edition, Little, Brown and Company, Boston.

[4] Bagłaj, M. (2004) Late-presenting congenital diaphragmmatic hernia in children: a clinical spectrum. Pediatric Surgery International, 20, 658-669. doi:10.1007/s00383-004-1269-5

[5] Thomas, S. and Kapur, B. (1991) Adult Bochdalek hernia clinical features, management and results of treatment. Japanese Journal of Surgery, 21, 114-119. doi:10.1007/BF02470876

[6] Barbiera, F., Nicastro, N., Finazzo, M., Lo Casto, A., Runza, G., Bartolotta, T.V. and Midiri, M. (2003) The role of MRI in traumatic rupture of the diaphragm. Our experience in three cases and review of the literature. $\mathrm{La}$ Radiologia Medica, 105, 188-194.

[7] Crandall, M., Popowich, D., Shapiro, M. and West, M. (2007) Posttraumatic hernias: Historical overview and review of the literature. The American Journal of Surgery, 73, 845-850.

[8] Puri, P. and Wester, T. (1997) Historical aspects of congenital diaphragmatic hernia. Pediatric Surgery International, 12, 95-100. doi:10.1007/BF01349971 
[9] Carvajal Balaguera J.J., Casas, M.S., Peña Gamarra L., Gómez Maestro P., Monterde García G. and Tello López I. (1995) Bochdalek's hernia in an adult with stomach volvulus and extrapulmonary sequestration. Archivos de Bronconeumología, 31, 287-289.

[10] Ayala, J.A., Naik-Mathuria, B. and Olutoye, O.O. (2008) Delayed presentation of congenital diaphragmatic hernia manifesting as combined-type acute gastric volvulus: A case report and review of the literature. Journal of Pediatric Surgery, 43, E35-39. doi:10.1016/j.jpedsurg.2007.11.015

[11] Horton, J.D., Hofmann, L.J. and Hetz, S.P. (2008) Presentation and management of Morgagni hernias in adults: A review of 298 cases. Surgical Endoscopy, 22, 14131420. doi:10.1007/s00464-008-9754-x

[12] Shah, R., Sabanathan, S., Mearns, A.J. and Choudhury, A.K. (1995) Traumatic rupture of diaphragm. The Annals of Thoracic Surgery, 60, 1444-1449. doi:10.1016/0003-4975(95)00629-Y

[13] Brusciano, L., Izzo, G., Maffettone, V,, Rossetti, G.,
Renzi, A., Napolitano, V,, Russo, G. and Del Genio, A. (2003) Laparoscopic treatment of Bochdalek hernia without the use of a mesh. Surgical Endoscopy, 17, 14971498. doi:10.1007/s00464-002-4288-0

[14] Meyer, G., Hüttl, T.P., Hatz, R.A. and Schildberg, F.W. (2000) Laparoscopic repair of traumatic diaphragmatic hernias. Surgical Endoscopy, 14, 1010-1014. doi: $10.1007 / \mathrm{s} 004640000206$

[15] Connor, D.J. (2006) Bochdalek hernia in a soldier. Journal of the Royal Naval Medical Service, 92, 75-77.

[16] Fei, L., Saviano, C., Moccia, F., del Genio, G., Trapani, V., Nunziale, A., Lombardi, G. and Cecchi, M. (2008) ePTFE soft tissue patch reconstruction of hemi diaphragmatic agenesis with late clinical presentation. Hernia, 12, 103-106. doi:10.1007/s10029-007-0254-z

[17] Cosenza, U.M., Raschellà, G.F., Giacomelli, L., Scicchitano, F., Simone, M., Cancrini, G., Zofrea, P. and Cancrini, A. (2004) The Bochdalek hernia in the adult: Case report and review of the literature. Giornale di Chirurgia, 25, 175-179. 